\title{
Chloroplastic ATP Synthase Alleviates Photoinhibition of Photosystem I in Tobacco Illuminated at Chilling Temperature
}

\author{
Ying-Jie Yang ${ }^{1,2}$, Shi-Bao Zhang ${ }^{1 *}$ and Wei Huang ${ }^{1 *}$ \\ ${ }^{1}$ Key Laboratory of Economic Plants and Biotechnology, Kunming Institute of Botany, Chinese Academy of Sciences, \\ Kunming, China, ${ }^{2}$ University of Chinese Academy of Sciences, Beijing, China
}

OPEN ACCESS

Edited by:

Vasilij Goltsev,

Sofia University, Bulgaria

Reviewed by:

Peter J. Gollan,

University of Turku, Finland

Vladimir Sukhov,

N. I. Lobachevsky State University

of Nizhny Novgorod, Russia

*Correspondence:

Shi-Bao Zhang

sbzhang@mail.kib.ac.cn

Wei Huang

huangwei@mail.kib.ac.cn

Specialty section:

This article was submitted to

Plant Abiotic Stress,

a section of the journal

Frontiers in Plant Science

Received: 15 May 2018

Accepted: 23 October 2018

Published: 14 November 2018

Citation:

Yang Y-J, Zhang S-B and Huang W (2018) Chloroplastic ATP Synthase Alleviates Photoinhibition of Photosystem I in Tobacco Illuminated at Chilling Temperature.

Front. Plant Sci. 9:1648.

doi: 10.3389/fp/s.2018.01648
Chloroplastic ATP synthase plays a significant role in the regulation of proton motive force (pmf) and proton gradient $(\Delta \mathrm{pH})$ across the thylakoid membranes. However, the regulation of chloroplastic ATP synthase at chilling temperature and its role in photoprotection are little known. In our present study, we examined the chlorophyll fluorescence, P700 signal, and electrochromic shift signal at $25^{\circ} \mathrm{C}$, and $6^{\circ} \mathrm{C}$ in tobacco (Nicotiana tabacum L. Cv. Samsun). Although photosynthetic electron flow through both PSI and PSII were severely inhibited at $6^{\circ} \mathrm{C}$, non-photochemical quenching and P700 oxidation ratio were largely increased. During the photosynthetic induction under high light, the formation of $p m f$ at $6^{\circ} \mathrm{C}$ was similar to that at $25^{\circ} \mathrm{C}$. However, the $\Delta \mathrm{pH}$ was significantly higher at $6^{\circ} \mathrm{C}$, owing to the decreased activity of chloroplastic ATP synthase $\left(g_{\mathrm{H}^{+}}\right)$. During illumination at $6^{\circ} \mathrm{C}$ and high light, a high $\Delta \mathrm{pH}$ made PSI to be highly oxidized, preventing PSI from photoinhibition. These results indicate that the downregulation of $\mathrm{gH}_{\mathrm{H}}$ is critical to the buildup of $\Delta \mathrm{pH}$ at low temperature, adjusting the redox state of $\mathrm{PSI}$, and thus preventing photodamage to PSI. Our findings highlight the importance of chloroplastic ATP synthase in photoprotection at chilling temperature.

Keywords: chilling temperature, chloroplastic ATP synthase, proton motive force, $\Delta \mathrm{pH}$, photosystem I, photoprotection

\section{INTRODUCTION}

Light drives photosynthesis in higher plants. However, excess excitation energy can induce photoinhibition in chloroplasts (Melis, 1999). Under environmental stresses, such as high-light intensities and drought conditions, photosystem II (PSII) is generally the most sensitive component whereas photosystem I (PSI) is relatively stable (Aro et al., 1993). However, at chilling-light stress, PSI is severely damaged, and the damage to PSII is often negligible in the chilling-sensitive plant cucumber (Havaux and Davaud, 1994; Sonoike and Terashima, 1994; Terashima et al., 1994; Barth and Krause, 1999). Photoinhibition of PSI severely affects linear electron flow (LEF), photosynthetic $\mathrm{CO}_{2}$ assimilation, photoprotection, and hence plant growth (Munekage et al., 2002, 2008; Suorsa et al., 2012, 2016; Brestic et al., 2015; Zivcak et al., 2015; Yamori et al., 2016). Furthermore, PSI recovers very slowly, which needs several days (Zhang and Scheller, 2004; Zivcak et al., 2015). Therefore, PSI photoinhibition has been regarded as an important reason for why some chilling-sensitive plants such as cucumber cannot survive at low temperature. 
At chilling-light stress, photoinhibition of PSI can be alleviated by the addition of methyl viologen that stimulates the oxidation of PSI reaction centers by accepting electrons from PSI (Sonoike et al., 1997; Barth and Krause, 1999). As a result, under such condition, PSI photoinhibition occurs when the PSI electron carriers are highly reduced. Tobacco is considered as a less chilling-sensitive species compared to cucumber (Barth and Krause, 1999). Specifically, PSI activity is less sensitive to low temperature associated with strong light in tobacco than in cucumber (Barth and Krause, 1999). However, mechanisms underlying the photoprotection of PSI at chilling-light stress in tobacco are not clear.

Recently, Miyake group reported that when electron carriers in PSI are highly reduced, excess light energy induced the production of reactive oxygen species (ROS) within the thylakoid membranes, and those ROS causes serious damage to PSI (Sejima et al., 2014; Takagi et al., 2016, 2017). Furthermore, the ROS-scavenging systems consisting of ascorbate peroxidase, and superoxide dismutase are insufficient to scavenge those ROS (Takagi et al., 2016). In order to prevent the production of ROS within the thylakoid membranes, PSI should be highly oxidized, diminishing the probability of electron donation from P700 to $\mathrm{O}_{2}$. The PSI redox state is mainly regulated by a proton gradient $(\Delta \mathrm{pH})$ across the thylakoid membranes (Yamamoto et al., 2016; Takagi et al., 2017). A higher $\Delta \mathrm{pH}$ slows down the oxidation of $\mathrm{PQH}_{2}$ at Cyt $b_{6} / f$, limiting the electron transfer to PSI, and thus contributing to the oxidation of P700 (Suorsa et al., 2012; Tikkanen and Aro, 2014; Tikkanen et al., 2015). As a result, the formation of a sufficient $\Delta \mathrm{pH}$ is important to optimize the redox state of PSI, and prevent photoinhibition of PSI under environmental stresses.

In chloroplasts, the formation of $\Delta \mathrm{pH}$ during photosynthesis is mainly dependent on two factors: (1) the accumulation of protons in the lumen from the water-splitting activity of PSII and from the electron transfer via Cyt $b_{6} / f$, which relies on photosynthetic electron transport; (2) the efflux of $\mathrm{H}^{+}$from lumen to the stromal side of thylakoid membranes (i.e., the activity of chloroplastic ATP synthase). In LEF, protons are released by water splitting in PSII and the quinone cycle in the Cyt $b_{6} / f$ complex, forming proton motive force (pmf) across the thylakoid membranes. During cyclic electron flow (CEF), electrons from either NADPH or ferredoxin are cycled back from PSI to the plastoquinone pool, generating a $\Delta \mathrm{pH}$ without reduction of $\mathrm{NADP}^{+}$(Johnson, 2011). In addition, chloroplastic ATP synthase controls the $\mathrm{H}^{+}$efflux activity and thus plays a significant role in the formation of $\Delta \mathrm{pH}$ (Kanazawa and Kramer, 2002; Rott et al., 2011; Kanazawa et al., 2017; Takagi et al., 2017). For example, at low $\mathrm{CO}_{2}$ concentration, the activity of chloroplastic ATP synthase is depressed to enhance $\Delta \mathrm{pH}$, modulating the thermal dissipation of excess light energy (Kanazawa and Kramer, 2002; Takagi et al., 2017). Under high light and fluctuating light, owing to the increased activity of chloroplastic ATP synthase, Arabidopsis mutants hope2, and $c f q$ showed lower $\Delta \mathrm{pH}$ than wild-type, resulting in severe photoinhibition of PSI and PSII (Takagi et al., 2017). As a result, coordination of photosynthetic electron flow, and chloroplastic ATP synthase regulate the $\Delta \mathrm{pH}$ formation, and photoprotection.

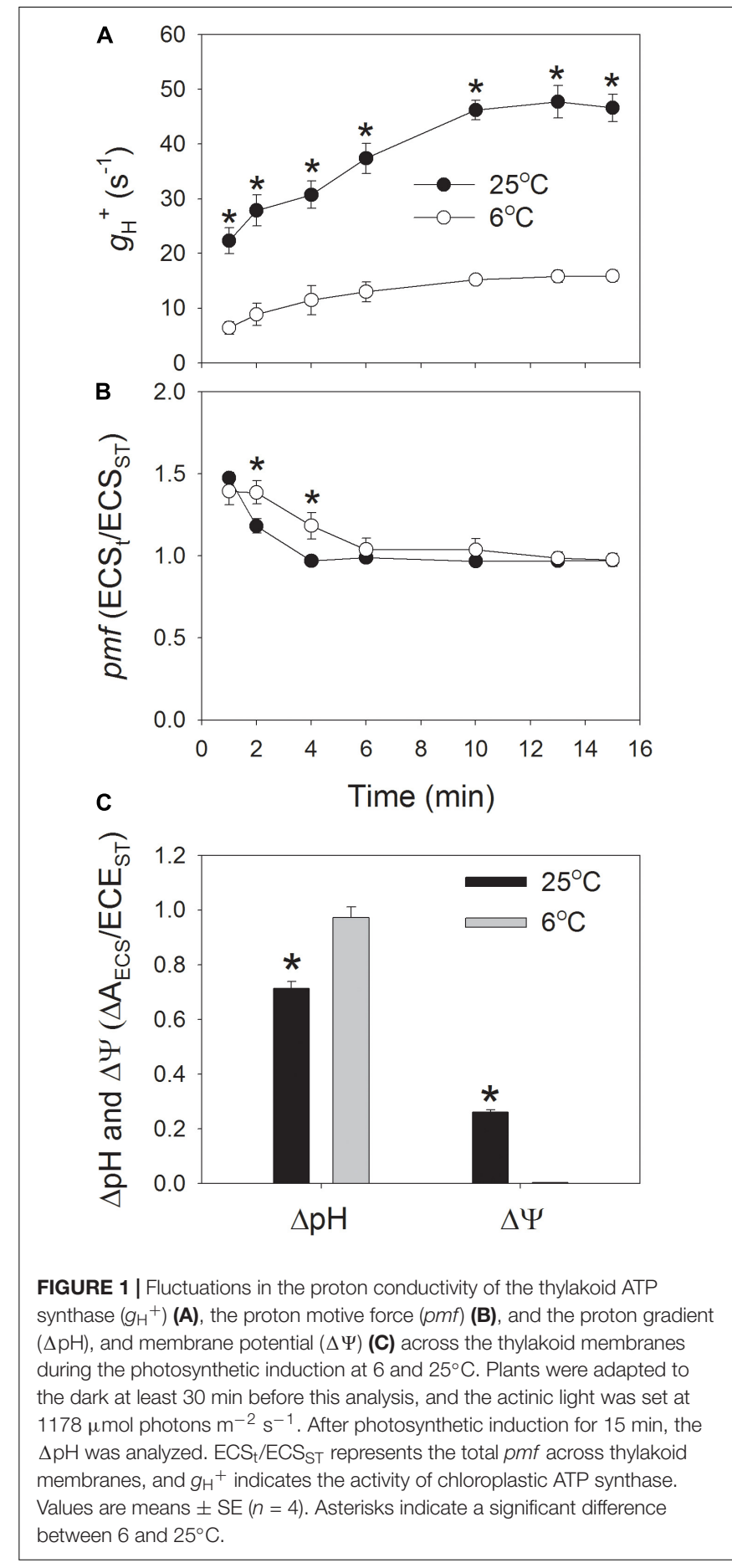

However, it is unclear whether alternative electron flow or chloroplastic ATP synthase is the critical component for the buildup of $\Delta \mathrm{pH}$ at chilling-light stress.

At chilling temperature, alternative electron flows including $\mathrm{CEF}$ and water-water cycle are considered to have important roles in stimulating $\Delta \mathrm{pH}$ formation (Hirotsu et al., 2004; Zhou et al., 2004; Huang et al., 2011, 2016b, 2017c). However, when illuminated at chilling temperature, the large decrease in 


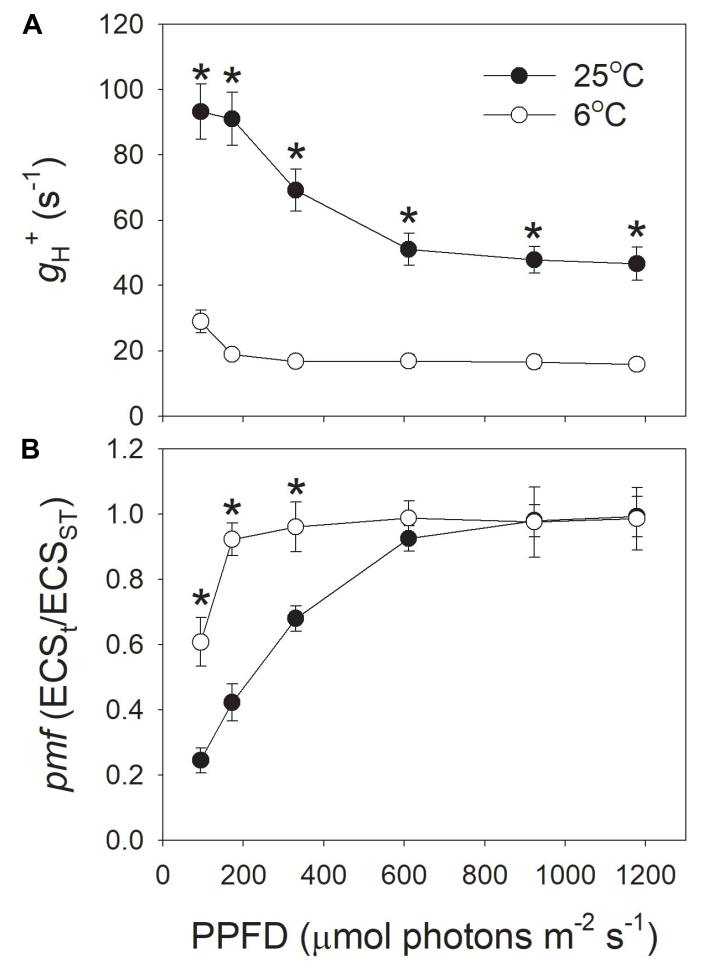

FIGURE 2 | Light intensity dependence of the proton conductivity of the thylakoid ATP synthase $\left(g_{\mathrm{H}^{+}}\right)$(A) and the pmf (B) across the thylakoid membranes at 6 and $25^{\circ} \mathrm{C}$. Before this analysis, leaves were illuminated at $1178 \mu \mathrm{mol}$ photons $\mathrm{m}^{-2} \mathrm{~s}^{-1}$ for $15 \mathrm{~min}$ to activate photosynthesis. Values for $\mathrm{gH}_{\mathrm{H}^{+}}$and $\mathrm{pmf}$ were obtained after exposure to each light intensity for 3 min. Values are means \pm SE $(n=4)$. Asterisks indicate a significant difference between 6 and $25^{\circ} \mathrm{C}$.

electron flow through both PSI and PSII was accompanied with an increase in $\Delta \mathrm{pH}$ for leaves of Calotropis gigantea (Huang et al., 2017c). As a result, the enhancement of $\Delta \mathrm{pH}$ at chilling temperature cannot be explained by the changes in ETRI and ETRII. We hypothesize that the chloroplastic ATP synthase is probably the key determinant of $\Delta \mathrm{pH}$ formation at chillinglight stress. In order to test this hypothesis, we examined the chlorophyll fluorescence, P700 signal, and electrochromic shift (ECS) signal at 25 and $6^{\circ} \mathrm{C}$ for leaves of a tobacco cultivar Samsun. Furthermore, the residual PSI and PSII activities after exposure to $1178 \mu \mathrm{mol}$ photons $\mathrm{m}^{-2} \mathrm{~s}^{-1}$ at $6^{\circ} \mathrm{C}$ for $100 \mathrm{~min}$ were determined.

\section{MATERIALS AND METHODS}

\section{Plant Materials}

In this study, we used tobacco (Nicotiana tabacum L. cv. Sumsan) to conduct experiments. This tobacco cultivar was chosen in particular because the PSI activity was insusceptible to low temperature and moderate light in it (Barth and Krause, 1999). Plants were cultivated in plastic pots in a phytotron with daily/night temperatures of $15 / 30^{\circ} \mathrm{C}$ and light condition of $95 \%$ sunlight. During the experimental period, plants were cultivated with sufficient water or nutrient. In the present study, mature, but not senescent leaves from 8-week-old plants were utilized for the experiments.

\section{Chlorophyll Fluorescence and P700 Measurements}

Light response curves were monitored by simultaneously recording chlorophyll fluorescence and P700 redox state using the Dual PAM-100 (Heinz Walz, Effeltrich, Germany). In the present study, red light $(635 \mathrm{~nm})$ was used as actinic light. To generate light response curves, dark-adapted mature leaves were illuminated at $25^{\circ} \mathrm{C}$ and $1178 \mu \mathrm{mol}$ photons $\mathrm{m}^{-2} \mathrm{~s}^{-1}$ for 15 min to activate photosynthetic sinks, followed by exposure to each light intensity $(1178,923,611,330,172,94 \mu \mathrm{mol}$ photons $\mathrm{m}^{-2} \mathrm{~s}^{-1}$ ) for $2 \mathrm{~min}$. Afterward, plants were transferred to $6^{\circ} \mathrm{C}$, and the same leaves were illuminated at $611 \mu \mathrm{mol}$ photons $\mathrm{m}^{-2}$ $\mathrm{s}^{-1}$ for $10 \mathrm{~min}$, followed by measurements of light response curves as conducted at $25^{\circ} \mathrm{C}$.

The chlorophyll fluorescence parameters were calculated as follows: $F_{\mathrm{v}} / F_{\mathrm{m}}=\left(F_{\mathrm{m}}-F_{\mathrm{o}}\right) / F_{\mathrm{m}}, \mathrm{Y}(\mathrm{II})=\left(F_{\mathrm{m}}{ }^{\prime}-F_{\mathrm{s}}\right) / F_{\mathrm{m}}{ }^{\prime}$ (Genty et al., 1989), non-photochemical quenching in PSII $(\mathrm{NPQ})=\left(F_{\mathrm{m}}-F_{\mathrm{m}}{ }^{\prime}\right) / F_{\mathrm{m}}{ }^{\prime} \cdot F_{\mathrm{o}}$ is the minimum fluorescence in the dark-adapted state. $F_{\mathrm{m}}$ and $F_{\mathrm{m}}{ }^{\prime}$ are the maximum fluorescence after dark-adapted and light-adapted, respectively. $F_{\mathrm{S}}$ is the lightadapted steady-state fluorescence. $F_{\mathrm{o}}$ and $F_{\mathrm{m}}$ were determined after dark adaptation for $30 \mathrm{~min}$. The PSI photosynthetic parameters were measured according to the method of Klughammer and Schreiber (2008). The maximum photooxidizable P700 $\left(P_{\mathrm{m}}\right)$ was determined to estimate the PSI activity (Huang et al., 2010a,b; Suorsa et al., 2012; Tikkanen et al., 2014; Yamori et al., 2016). The effective photochemical quantum yield of PSI was measured as $\mathrm{Y}(\mathrm{I})=\left(P_{\mathrm{m}}{ }^{\prime}-P\right) / P_{\mathrm{m}}$. The quantum yield of PSI non-photochemical energy dissipation due to donor side limitation was calculated as $\mathrm{Y}(\mathrm{ND})=P / P_{\mathrm{m}}$. The quantum yield of non-photochemical energy dissipation due to the acceptor side limitation was measured as $\mathrm{Y}(\mathrm{NA})=\left(P_{\mathrm{m}}-P_{\mathrm{m}}{ }^{\prime}\right) / P_{\mathrm{m}}$.

The rate of photosynthetic electron transport was calculated as: $\mathrm{ETRII}=\mathrm{Y}(\mathrm{II}) \times \mathrm{PPFD} \times 0.85 \times 0.5$, $\mathrm{ETRI}=\mathrm{Y}(\mathrm{I}) \times \mathrm{PPFD} \times 0.85 \times 0.5$, where 0.5 is the proportion of absorbed light reaching PSI, or PSII, and 0.85 is the fraction of the incident light absorbed by leaves. The apparent rate of CEF was estimated as ETRI - ETRII (Huang et al., 2012, 2015, 2017b, 2018b; Zivcak et al., 2013), and the relative contribution of CEF to total electron flow was estimated as ETRI/ETRII ratio (Yamori et al., 2011, 2015).

\section{Electrochromic Shift (ECS) Analysis}

The ECS signal was examined as the absorbance change at $515 \mathrm{~nm}$ by using a DUAL-PAM-100 (Walz, Effeltrich, and Germany) equipped with a P515/535 emitter-detector module (Walz). Plants were first dark adapted for $30 \mathrm{~min}$ to measure the $515 \mathrm{~nm}$ absorbance change induced by a single turnover flash $\left(\mathrm{ECS}_{\mathrm{ST}}\right)$. Afterward, we detected the ECS signal during photosynthetic induction at a high light of $1178 \mu \mathrm{mol}$ photons $\mathrm{m}^{-2} \mathrm{~s}^{-1}$, and the slow relaxation of the ECS signal were analyzed after exposure for $15 \mathrm{~min}$. Afterward, the ECS signal were 

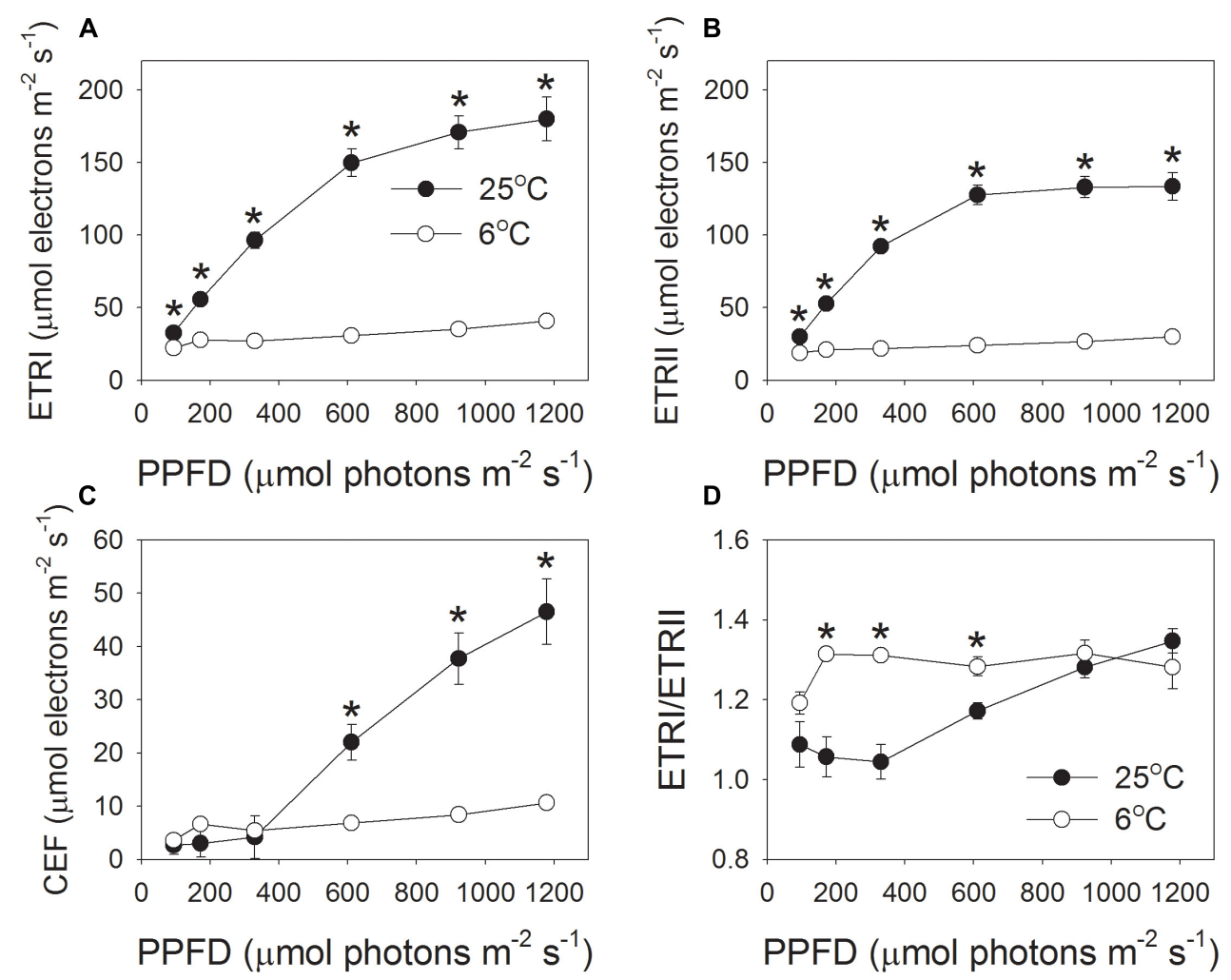

FIGURE 3 | Light intensity dependence of the photosynthetic electron flow through PSI and PSII at $6^{\circ} \mathrm{C}$ and $25^{\circ} \mathrm{C}$. (A) ETRI, electron transport rate through PSI; (B) ETRII, electron transport rate through PSII; (C) CEF, cyclic electron flow around PSI; (D) ETRI/ETRII ratio. Values are means \pm SE ( $n=4)$. Asterisks indicate a significant difference between $6^{\circ} \mathrm{C}$ and $25^{\circ} \mathrm{C}$.

recorded after exposure to each light intensity (1178, 923, 611, 330, 172, and $94 \mu \mathrm{mol}$ photons $\mathrm{m}^{-2} \mathrm{~s}^{-1}$ ) for $2 \mathrm{~min}$, during which 1-s dark pulse was applied to estimate the values of $\mathrm{ECS}_{t}$ and $\mathrm{g}_{\mathrm{H}}{ }^{+}$at each light intensity. The ECS dark interval

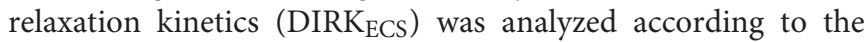
method of Sacksteder et al. (2001) and Takizawa et al. (2008), calculating $p m f$ and $g_{\mathrm{H}}{ }^{+}$. The slow relaxation of the ECS signal is used to analyze $\Delta \mathrm{pH}$ and the membrane potential $(\Delta \Psi)$ across the thylakoid membranes. All $\mathrm{ECS}_{\mathrm{t}}$ and $\Delta \mathrm{pH}$ levels were normalized against $\mathrm{ECS}_{\mathrm{ST}}$. This normalization accounted for changes in leaf thickness and chloroplast density between leaves (Takizawa et al., 2008; Wang et al., 2015). The activity of chloroplastic ATP synthase $\left(g_{\mathrm{H}}{ }^{+}\right)$was estimated as the inverse of the decay time constant $\left[1 / \tau_{\mathrm{ECS}}\right]$ by fitting the first $300 \mathrm{~ms}$ of the decay curve with a first-order exponential decay kinetic (Sacksteder and Kramer, 2000; Cruz et al., 2005).

\section{Photoinhibitory Treatment}

Before chilling-light treatment, whole plants were dark-adapted at $25^{\circ} \mathrm{C}$ for at least $30 \mathrm{~min}$ to measure $P_{\mathrm{m}}$ and $F_{\mathrm{v}} / F_{\mathrm{m}}$. Afterward, intact leaves were illuminated at $1178 \mu \mathrm{mol}$ photons $\mathrm{m}^{-2} \mathrm{~s}^{-1}$ and $6^{\circ} \mathrm{C}$ for $100 \mathrm{~min}$, and then values of $P_{\mathrm{m}}$ and $F_{\mathrm{V}} / F_{\mathrm{m}}$ were measured after dark adaptation for $30 \mathrm{~min}$ at $25^{\circ} \mathrm{C}$.

\section{Statistical Analysis}

We used independent $T$-test to detect differences between 25 and $6^{\circ} \mathrm{C}$. All statistical analyses were conducted using SPSS 16.0 software.

\section{RESULTS}

\section{Effects of Chilling Temperature on pmf and the Activity of Chloroplastic ATP Synthase}

In order to understand the regulation of $p m f$ at low temperature, ECS signal was determined during photosynthetic induction at $1178 \mu \mathrm{mol}$ photons $\mathrm{m}^{-2} \mathrm{~s}^{-1}$, and we analyzed $p m f$ and proton conductance of chloroplastic ATP synthase $\left(g_{\mathrm{H}}{ }^{+}\right)$. After onset of $\mathrm{AL}, \mathrm{g}_{\mathrm{H}}{ }^{+}$was low and gradually increased to the maximum value at approximately $10 \mathrm{~min}$ (Figure 1A). During the whole phase of photosynthetic induction, the values of $g_{\mathrm{H}}{ }^{+}$were significantly lower at $6^{\circ} \mathrm{C}$ when compared to $25^{\circ} \mathrm{C}$ (Figure 1A). After illumination at $1178 \mu \mathrm{mol}$ photons $\mathrm{m}^{-2} \mathrm{~s}^{-1}$ for $15 \mathrm{~min}$, the value of $\mathrm{g}_{\mathrm{H}}{ }^{+}$at $6^{\circ} \mathrm{C}$ was just $34 \%$ of that at $25^{\circ} \mathrm{C}$, indicating that the activity of chloroplastic ATP synthase was largely depressed in tobacco leaves when chilled at high light. Because the activity of chloroplastic ATP synthase can significantly affect the buildup of $p m f$, the performance of $p m f$ during photosynthetic induction 
was also monitored. When dark-adapted leaves were transferred to the high light, the pmf was rapidly formed in the first $1 \mathrm{~min}$ and gradually relaxed over time (Figure 1B). After exposure for 2 and $4 \mathrm{~min}$, the values of $p m f$ at $6^{\circ} \mathrm{C}$ were significantly higher than that at $25^{\circ} \mathrm{C}$. However, during further induction phase, the total pmf did not differ significantly between 25 and $6^{\circ} \mathrm{C}$ (Figure 1B). The $p m f$ is energetically composed of two components, $\Delta \mathrm{pH}$, and $\Delta \Psi$, and both them were analyzed after photosynthetic induction for $15 \mathrm{~min}$. Interestingly, $\Delta \mathrm{pH}$ was significantly increased but $\Delta \Psi$ was largely depressed at the low temperature (Figure 1C). This result indicated that when tobacco leaves were chilled at high light, the thylakoid lumen became more acid although the total pmf did not change. These results were different from the pmf formation at low $\mathrm{CO}_{2}$ concentration. At a low $\mathrm{CO}_{2}$ concentration of $10 \mathrm{ppm}$, the decrease in ATP synthase activity led to the significant increase in pmf (Sukhov et al., 2016) Meanwhile, $\Delta \mathrm{pH}$ was stimulated to favor photoprotection. However, $\Delta \Psi$ was weakly influenced. Therefore, the partitioning of pmf into $\Delta \mathrm{pH}$ at chilling temperature was probably regulated by the counter-ion fluxes across the thylakoid membrane.

In addition, we examined the light intensity dependence of $g_{\mathrm{H}}{ }^{+}$and $p m f$ at $25^{\circ} \mathrm{C}$, and $6^{\circ} \mathrm{C}$ (Figure 2). The results indicated that the values for $g_{\mathrm{H}}{ }^{+}$under all light intensities were largely depressed by the low temperature of $6^{\circ} \mathrm{C}$ (Figure 2A), indicating the decreased activity of chloroplastic ATP synthase at $6^{\circ} \mathrm{C}$, irrespective of the light intensity. Concomitantly, the total $p m f$ was significantly enhanced under light intensities below $330 \mu \mathrm{mol}$ photons $\mathrm{m}^{-2} \mathrm{~s}^{-1}$ (Figure 2B). These results suggested that the decrease in $g_{\mathrm{H}}{ }^{+}$contributed to the enhancement of pmf at chilling temperature.

\section{Effect of Low Temperature on Photosynthetic Electron Flow}

In order to understand the effect of low temperature on proton influx activity, the light intensity dependence of photosynthetic electron flow was measured at 6 and $25^{\circ} \mathrm{C}$. The rates of electron flow through PSI and PSII were severely inhibited by the low temperature, especially under high light intensities (Figure 3). For example, at the high light of $1178 \mu \mathrm{mol}$ photons $\mathrm{m}^{-2} \mathrm{~s}^{-1}$, values for ETRI at 25 and $6^{\circ} \mathrm{C}$ were 180 and $41 \mu \mathrm{mol}$ electrons $\mathrm{m}^{-2} \mathrm{~s}^{-1}$, respectively, (Figure 3A). Concomitantly, values for ETRII were $133\left(25^{\circ} \mathrm{C}\right)$ versus $30 \mu \mathrm{mol}$ electrons $\mathrm{m}^{-2} \mathrm{~s}^{-1}$ $\left(6^{\circ} \mathrm{C}\right)$ (Figure 3B). As a result, values for CEF at $1178 \mu \mathrm{mol}$ photons $\mathrm{m}^{-2} \mathrm{~s}^{-1}$, estimated as ETRI minus ETRII, were $47 \mu \mathrm{mol}-11 \mu \mathrm{mol}$ electrons $\mathrm{m}^{-2} \mathrm{~s}^{-1}$, respectively, (Figure 3C). Interestingly, the values of ETRI, ETRII, and CEF at $1178 \mu \mathrm{mol}$ photons $\mathrm{m}^{-2} \mathrm{~s}^{-1}$ decreased to approximately 23\% when leaves were transferred from 25 to $6^{\circ} \mathrm{C}$ (Figure 3). Furthermore, the value of ETRI/ETRII ratio at this strong light did not differ significantly between 25 and $6^{\circ} \mathrm{C}$ (Figure 3D).

\section{Effects of Chilling Temperature on PSII Energy Quenching and PSI Redox State}

Because the responses of PSI and PSII activities to excess light energy are significantly correlated to the redox state of electron transfer chains (Munekage et al., 2002, 2004;
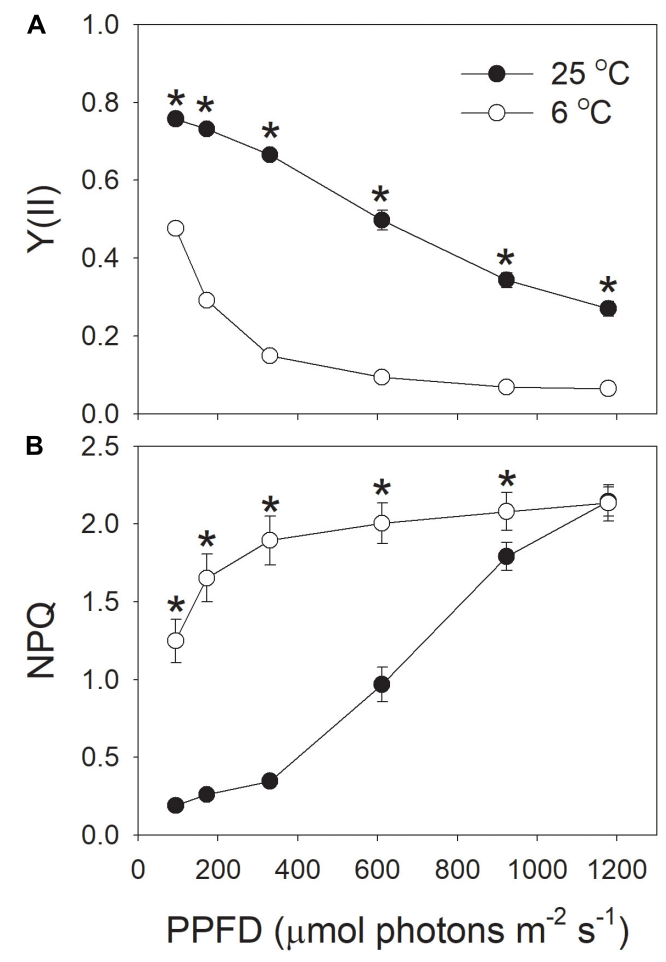

FIGURE 4 | (A,B) Light intensity dependence of Y(II) (the effective quantum yield of PSIl photochemistry) and NPQ (non-photochemical quenching in PSII) at 6 and $25^{\circ} \mathrm{C}$. Values are means $\pm \operatorname{SE}(n=4)$. Asterisks indicate a significant difference between 6 and $25^{\circ} \mathrm{C}$.

Suorsa et al., 2012, 2016; Brestic et al., 2016; Takagi et al., 2016; Yamori et al., 2016), the parameters related to PSII energy quenching and PSI redox state as a function of the incident light intensity were measured.

At the chilling temperature of $6^{\circ} \mathrm{C}$, the quantum yield of PSII photochemistry [Y(II)] largely decreased under all light intensities, as compared to $25^{\circ} \mathrm{C}$ (Figure 4A), suggesting the decreased ability of plants to utilize the product of LEF, partly due to reduced Calvin-Benson cycle activity. This result was consistent with previous studies (Huang et al., 2011, 2016b, 2017c). Meanwhile, the NPQ was up-regulated to harmlessly dissipate excess light energy, especially at low light intensities (Figure 4B). At $6^{\circ} \mathrm{C}$, NPQ was saturated at approximately $611 \mu \mathrm{mol}$ photons $\mathrm{m}^{-2} \mathrm{~s}^{-1}$. At this light intensity, the value of $\mathrm{NPQ}$ at $25^{\circ} \mathrm{C}$ was half that at $6^{\circ} \mathrm{C}$. At the high light of $1178 \mu \mathrm{mol}$ photons $\mathrm{m}^{-2} \mathrm{~s}^{-1}$, the NPQ induction at $6^{\circ} \mathrm{C}$ was very similar to that at $25^{\circ} \mathrm{C}$.

The effective quantum yield of PSI [Y(I)] decreased gradually with increasing light intensity (Figure 5A), in accordance with previous reported results (Huang et al., 2011, 2017c; Kono et al., 2014). Similar to Y(II), Y(I) was largely inhibited by the low temperature (Figure 5A). With the increase in light intensity, the quantum yield of PSI non-photochemical quenching due to the donor side limitation [Y(ND)] gradually increased (Figure 5B), as expected from previous results reported in wild-type plants (Munekage et al., 2002, 2004; 

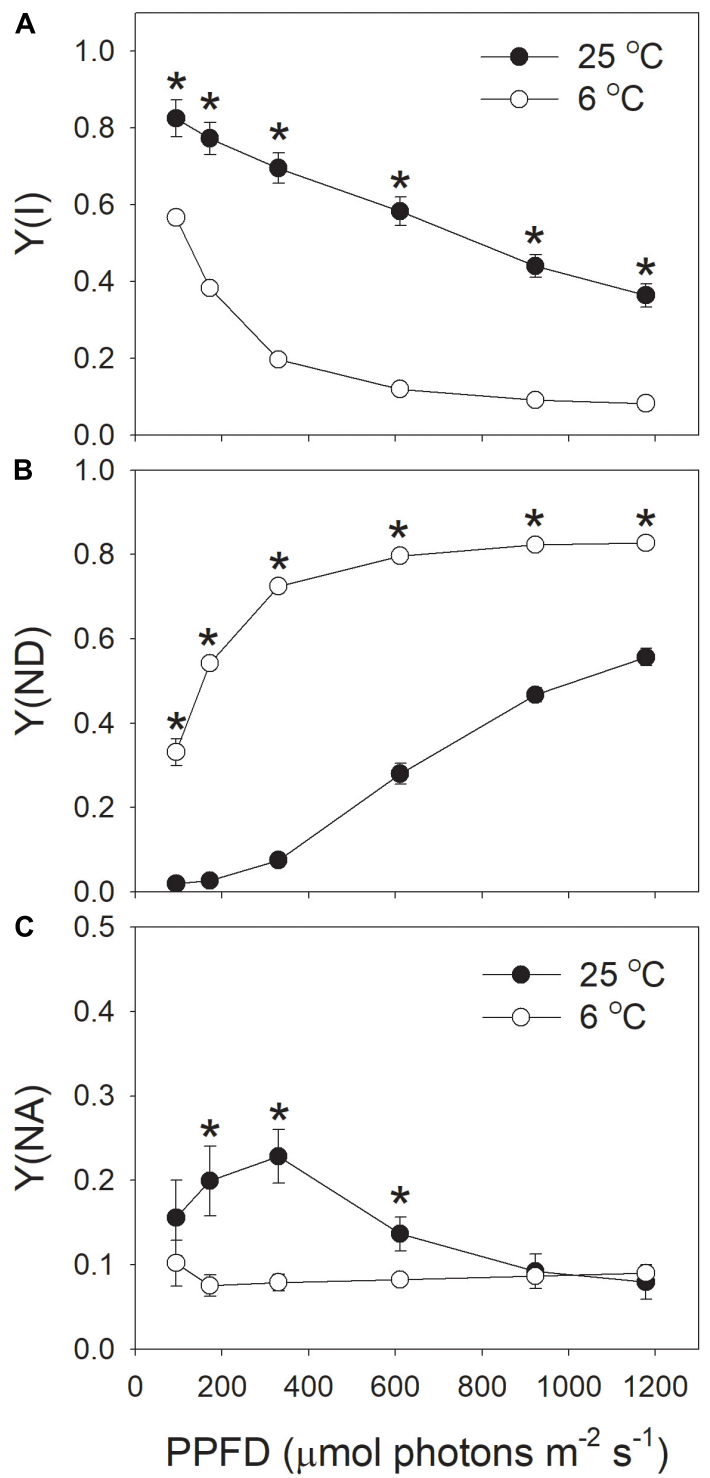

FIGURE 5 | Light intensity dependence of PSI redox state at 6 and $25^{\circ} \mathrm{C}$. (A) $Y(I)$, the quantum yield of PSI photochemistry. (B) Y(ND), the quantum yield of PSI non-photochemical energy dissipation due to the donor-side limitation. (C) Y(NA), the quantum yield of PSI non-photochemical energy due to the acceptor-side limitation. Values are means \pm SE $(n=4)$. Asterisks indicate a significant difference between 6 and $25^{\circ} \mathrm{C}$.

Kono et al., 2014). Furthermore, under all light intensities, values for $\mathrm{Y}(\mathrm{ND})$ were largely higher at $6^{\circ} \mathrm{C}$ than at $25^{\circ} \mathrm{C}$, indicating that more $\mathrm{P} 700$ was in the oxidized state when leaves were illuminated at $6^{\circ} \mathrm{C}$. The quantum yield of PSI nonphotochemical quenching due to the acceptor side limitation [Y(NA)] was maintained at 0.1 when illuminated at $6^{\circ} \mathrm{C}$ (Figure 5C). By comparison, the value of $\mathrm{Y}(\mathrm{NA})$ at $25^{\circ} \mathrm{C}$ and high light was also maintained at 0.1 (Figure 5C). These results indicated that the over-reduction of electron carriers in PSI was prevented in these tobacco leaves illuminated at chilling temperature.
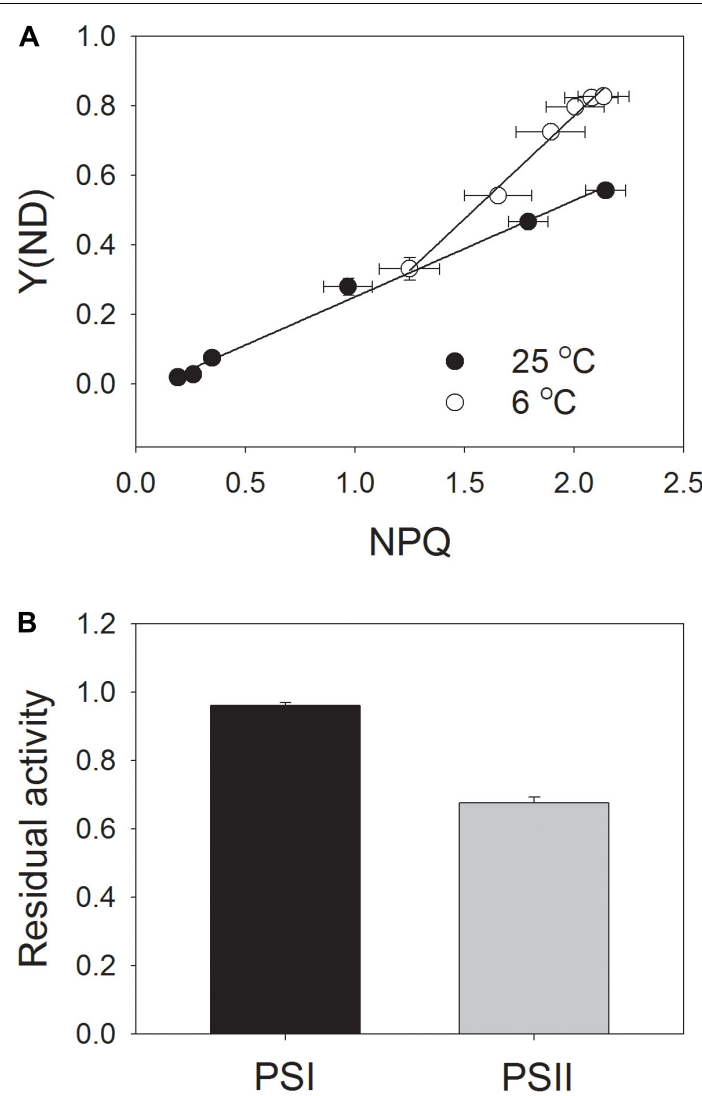

FIGURE 6 | Correlation between NPQ and Y(ND) (A) and residual activity of PSI and PSII (B) after exposure to $1178 \mu \mathrm{mol}$ photons $\mathrm{m}^{-2} \mathrm{~s}^{-1}$ at $6^{\circ} \mathrm{C}$ for $100 \mathrm{~min}$. Data of Figures 4B, 5B were used to analyze the correlation between NPQ and $Y(N D)$. After the chilling-light treatment, the $P_{m}$ (maximum photo-oxidizable P700 content) and $F_{\mathrm{v}} / F_{\mathrm{m}}$ were measured, and the data were normalized to $P_{\mathrm{m}}$ and $F_{\mathrm{v}} / F_{\mathrm{m}}$ before treatment and are represented as the residual activity of PSII and PSI after chilling-light treatment. Values are means $\pm \operatorname{SE}(n=4)$.

Next, we analyzed the correlation between NPQ and Y(ND). We observed that, under high light, the same value of NPQ was accompanied with a higher $\mathrm{Y}(\mathrm{ND})$ at the chilling temperature (Figure 6A). This results suggested that the enhancement of $\Delta \mathrm{pH}$ at chilling temperature was more important for oxidizing PSI than for inducing NPQ.

\section{Effect of Chilling Temperature on Photoinhibition}

In order to understand the role of chloroplastic ATP synthase in photoprotection for PSI at chilling temperature, intact tobacco leaves were exposed to $6^{\circ} \mathrm{C}$ and $1178 \mu \mathrm{mol}$ photons $\mathrm{m}^{-2} \mathrm{~s}^{-1}$ for $100 \mathrm{~min}$, and the residual PSI and PSII activities were determined (Figure 6B). Interestingly, the value of $P_{\mathrm{m}}$ just decreased by $4 \%$ after this chilling-light treatment, indicating that PSI activity was not susceptible to this chilling-light stress. This result was consistent with the performance of PSI redox state as indicated in light response curves. By comparison, $F_{\mathrm{v}} / F_{\mathrm{m}}$ decreased by $32 \%$, indicating a moderate photoinhibition of PSII. 


\section{DISCUSSION}

\section{Tolerance of PSI Activity to Short-Term Chilling-Light Stress}

Our results strongly indicated that, in leaves of the tobacco cultivar Samsun, the PSI activity hardly decreased after exposure to $6^{\circ} \mathrm{C}$ and $1178 \mu \mathrm{mol}$ photons $\mathrm{m}^{-2} \mathrm{~s}^{-1}$ for $100 \mathrm{~min}$ (Figure 6B). Indeed, the tobacco cultivar Samsun is much less sensitive to chilling-light stress than the chilling-sensitive plant cucumber. For leaf disks of the tobacco cultivar Samsun, no inhibition of each photosystem was observed after $2 \mathrm{~h}$ illumination with $200 \mu \mathrm{mol}$ photons $\mathrm{m}^{-2} \mathrm{~s}^{-1}$ at $4^{\circ} \mathrm{C}$, but cucumber (Cucumis sativus L. cv. Mervita) leaf disks showed a decrease of $55 \%$ in PSI activity (Barth and Krause, 1999). These results suggest that the tobacco (cv. Samsun) leaves should have feasible mechanisms to prevent PSI against photoinhibition under chilling-light stress.

The mechanism of PSI photoinhibition under natural field conditions is dependent on plant species. A typical scheme of PSI photoinhibition proposes that the ROS produced within PSI cause PSI photoinhibition when electron carriers in PSI are highly reduced (Munekage et al., 2002; Takagi et al., 2016, 2017). However, ROS produced in the chloroplast stroma cause photoinhibition of PSI in some shade-establishing plants such as Psychotria henryi, P. rubra, and Nephrolepis falciformis (Huang et al., 2016c, 2017a, 2018c). At chilling temperature, lightinduced photoinhibition of PSI could be alleviated by the addition of methyl viologen (Sonoike et al., 1997; Barth and Krause, 1999), which stimulates the production of ROS at the stromal region by accepting electrons from PSI. Therefore, a strong stromal sink prevents PSI photoinhbition. For the intact leaves of tobacco ( $c v$. Samsun), the PSI reaction centers was highly oxidized at $6^{\circ} \mathrm{C}$ and $1178 \mu \mathrm{mol}$ photons $\mathrm{m}^{-2} \mathrm{~s}^{-1}$ (Figure 5B). As a result, the probability of electron donation from P700 to $\mathrm{O}_{2}$ was suppressed, preventing the production of ROS in PSI and thus leading to the stability of PSI activity. In addition, PSII activity significantly decreased during the chilling-light treatment. Because PSII photoinhibition can decrease the electron transport to PSI and thus diminishes the production of ROS in PSI (Tikkanen et al., 2014; Huang et al., 2016a; Sukhov, 2016; Surova et al., 2016), the significant PSII photoinhibition may be another mechanism for protecting PSI against photoinhibition in tobacco leaves chilled at high light.

\section{In vivo Regulation of PSI Redox State at Chilling-Light Stress}

Proton motive force plays a critical role in photoprotection for PSIthrough regulation of the redox state of PSI (Yamamoto et al., 2016;Shikanai and Yamamoto, 2017; Takagi et al., 2017). In order to understand why PSI was highly oxidized when the tobacco ( $c v$. Samsun) leaves were chilled at high light, we determined the pmf during photosynthetic induction at $1178 \mu \mathrm{mol}$ photons $\mathrm{m}^{-2} \mathrm{~s}^{-1}$ and $6^{\circ} \mathrm{C}$. Interestingly, we found that high levels of pmf were observed during the photosynthetic induction at $6^{\circ} \mathrm{C}$ (Figure 1B). Furthermore, after induction for
$15 \mathrm{~min}$, the value of $\Delta \mathrm{pH}$ was significantly higher at $6^{\circ} \mathrm{C}$ than at $25^{\circ} \mathrm{C}$ (Figure 1C). This high level of $\Delta \mathrm{pH}$ controls electron transport to PSI, which involves two different mechanisms. Firstly, $\Delta \mathrm{pH}$ slows down water splitting at the oxygen-evolving complex and induces NPQ to dissipate excessively absorbed light energy as heat from PSII antennae (Niyogi et al., 1998). The second is down-regulation of oxidation of $\mathrm{PQH}_{2}$ at Cyt $b_{6} / f$ complex, which contributes to oxidation of P700 when the acceptor side of PSI is open (Munekage et al., 2002, 2004; Suorsa et al., 2012, 2016; Yamamoto et al., 2016). These mechanisms control the rate of electron transfer from PSII to PSI, and prevent the over-reduction of electron carriers in PSI, protecting PSI activity under high light and fluctuating light (Munekage et al., 2002; Suorsa et al., 2012, 2016; Kono et al., 2014; Yamori et al., 2016). Once the formation of $\Delta \mathrm{pH}$ was inhibited, PSI was very susceptible to high light and fluctuating light (Munekage et al., 2002; Suorsa et al., 2012; Tikkanen et al., 2014; Yamori et al., 2016; Kanazawa et al., 2017; Takagi et al., 2017). The light response curves indicated that the values of NPQ and $\mathrm{Y}(\mathrm{ND})$ were highly enhanced at the low temperature (Figures 4B, 5B), accompanying with high levels of pmf and low levels of $g_{\mathrm{H}}{ }^{+}$(Figure 2). These results also suggested the upregulation of $\Delta \mathrm{pH}$ at chilling-light stress. Therefore, the formation of an enhanced $\Delta \mathrm{pH}$ under chillinglight stress optimized the redox state of P700 in PSI and minimized ROS production within PSI, thus preventing PSI photoinhibition.

\section{In vivo Regulation of Proton Motive Force at Chilling-Light Stress}

Next, we examined the critical factor for the formation of an enhanced $\Delta \mathrm{pH}$ at $1178 \mu \mathrm{mol}$ photons $\mathrm{m}^{-2} \mathrm{~s}^{-1}$ and $6^{\circ} \mathrm{C}$. The formation of $\Delta \mathrm{pH}$ is determined by two factors: (i) the $\mathrm{H}^{+}$influx activity in dependence on photosynthetic electron flow including LEF and CEF; and (ii) the $\mathrm{H}^{+}$efflux activity modulated by chloroplastic ATP synthase. We observed that both the LEF and CEF were largely depressed at chilling temperature (Figure 3). Furthermore, the ETRI/ETRII ratio at $1178 \mu \mathrm{mol}$ photons $\mathrm{m}^{-2} \mathrm{~s}^{-1}$ did not change significantly between 25 and $6^{\circ} \mathrm{C}$ (Figure 3D), indicating that the chilling temperature hardly influenced the relative contribution of CEF to total electron transport at this high light. By comparison, ETRI/ETRII ratio was enhanced at light intensities below $611 \mu \mathrm{mol}$ photons $\mathrm{m}^{-2} \mathrm{~s}^{-1}$ (Figure 3D). These results indicated that at low temperature CEF might play an important role in regulation of $\Delta \mathrm{pH}$ at low and moderate light intensities but was less important at high light conditions. Usually, in some stress conditions such as drought, the high levels of NPQ under high light are accompanied with high levels of CEF (Huang et al., 2012; Zivcak et al., 2013, 2014), because the CEF-dependent generation of $\Delta \mathrm{pH}$ can activate thermal energy dissipation. Now that the up-regulation of $\Delta \mathrm{pH}$ at $1178 \mu \mathrm{mol}$ photons $\mathrm{m}^{-2} \mathrm{~s}^{-1}$ and $6^{\circ} \mathrm{C}$ could not be explained by the changes in LEF and CEF, we paid attention to the rate of $\mathrm{H}+$ efflux from the lumen to stroma, which is managed by the chloroplastic ATP synthase. 
Chloroplastic ATP synthase significant affects $\Delta \mathrm{pH}$ and thus regulates photosynthetic electron flow (Rott et al., 2011;Kanazawa et al., 2017; Takagi et al., 2017; Huang et al., 2018a). Once the activity of chloroplastic ATP synthase $\left(g_{\mathrm{H}}{ }^{+}\right)$ is strongly repressed, the over-acidification of the thylakoid lumen restricts the assimilation capacity and LEF (Rott et al., 2011). Furthermore, once the $g_{\mathrm{H}}{ }^{+}$is enhanced in $c f q$ and hope 2 mutants of Arabidopsis thaliana, the formation of $\Delta \mathrm{pH}$ is not sufficient, which subsequently causes photodamage to PSI and PSII (Kanazawa et al., 2017; Takagi et al., 2017). In pgr5 mutant of $A$. thaliana, the increased $g_{\mathrm{H}}{ }^{+}$impairs the buildup of $\Delta \mathrm{pH}$, leading to the over-reduction of PSI electron carriers and thus causing photoinhibition of PSI (Avenson et al., 2005; Suorsa et al., 2012, 2016; Wang et al., 2015; Shikanai and Yamamoto, 2017). As a result, $g_{\mathrm{H}}{ }^{+}$is an important valve for photoprotection and plant growth. Interestingly, we here found that the $g_{\mathrm{H}}{ }^{+}$values strongly decreased at the low temperature (Figures 1A, 2A), which restricted the rate of $\mathrm{H}^{+}$efflux from thylakoid lumen to stroma. These results indicate that the chloroplastic ATP synthase, but not CEF, is critical to the buildup of an enhanced $\Delta \mathrm{pH}$ at chilling temperature and high light, which provides new insight into the importance of chloroplastic ATP synthase in tolerance to low temperature.

At chilling temperature, the $\mathrm{CO}_{2}$ assimilation and photorespiration were extremely inhibited, based on the results of photosynthetic electron flow (Figure 3 ). The rate of $\mathrm{CO}_{2}$ assimilation can affect the modulation of pmf and $\Delta \mathrm{pH}$ (Kanazawa and Kramer, 2002; Takagi et al., 2017). However, this process depends on the regulation of chloroplastic ATP synthase. In Arabidopsis thaliana mutants pgr5 and hope2, the disturbed regulation of chloroplastic ATP synthase impaired the formation of pmf and $\Delta \mathrm{pH}$ (Avenson et al., 2005; Takagi et al., 2017), causing photoinhibition of PSI under high light and fluctuating light. In chloroplasts, the activity of chloroplastic ATP synthase is thermodynamically regulated by the stromal ATP/ADP ratio. Takizawa et al. (2008) reported that $g_{\mathrm{H}}{ }^{+}$was decreased by Pi deficiency in chloroplasts. Under conditions of high light and low temperature, the ATP/ADP ratio in chloroplasts increases due to the restriction of $\mathrm{CO}_{2}$ assimilation, leading to the decreased availability of ADP, and Pi. Consequently, the activity of chloroplastic ATP synthase was depressed, leading to lower values of $g_{\mathrm{H}^{+}}{ }^{+}$.

\section{REFERENCES}

Aro, E. M., Virgin, I., and Andersson, B. (1993). Photoinhibition of photosystem II. Inactivation, protein damage and turnover. Biochim. Biophys. Acta 1143, 113-134. doi: 10.1016/0005-2728(93)90134-2

Avenson, T. J., Cruz, J. A., Kanazawa, A., and Kramer, D. M. (2005). Regulating the proton budget of higher plant photosynthesis. Proc. Natl. Acad. Sci. U.S.A. 102, 9709-9713. doi: 10.1073/pnas.0503952102

Barth, C., and Krause, G. H. (1999). Inhibition of photosystems I and II in chilling-sensitive and chilling-tolerant plants under light and low-temperature stress. Zeitschrift Naturforschung 54c, 645-657. doi: 10.1515/znc-19999-1006

\section{CONCLUSION}

In summary, our results indicate that chloroplastic ATP synthase plays a critical role in the regulation of $\Delta \mathrm{pH}$ at chilling temperature and prevents PSI from photoinhibition. When plants are subjected to chilling-light stress, they are at risk of producing ROS in PSI. However, chloroplastic ATP synthase detects excess excitation energy by the slower ATP consumption rate or an unknown regulatory factor, and the decreased activity of chloroplastic ATP synthase contributes to the up-regulation of $\Delta \mathrm{pH}$. This high level of $\Delta \mathrm{pH}$ slows down the electron transfer from PSII to PSI and avoids the over-reduction state in PSI, which would be beneficial for minimizing the production of ROS in PSI and preventing PSI photoinhibition. From the present study we propose that the chloroplastic ATP synthase, but not alternative electron flow, is critical for the formation of a sufficient $\Delta \mathrm{pH}$ at low temperature and high light. Chloroplastic ATP synthase is a potential target to improve $\mathrm{H}^{+}$efflux management and increase tolerance against low temperature stress under field conditions. Further study is needed to clarify the effect of impairment of $g_{\mathrm{H}}{ }^{+}$regulation on PSI redox state and PSI photoinhibition at chilling-light stress.

\section{AUTHOR CONTRIBUTIONS}

WH and S-BZ designed the study. Y-JY and WH conducted the experiments. Y-JY, S-BZ, and WH analyzed the data. Y-JY wrote the manuscript with significant input from S-BZ and $\mathrm{WH}$.

\section{FUNDING}

This work was supported by National Natural Science Foundation of China (Grant No. 31670343), and Youth Innovation Promotion Association of the Chinese Academy of Sciences (Grant No. 2016347).

\section{ACKNOWLEDGMENTS}

We thank Dr. Jing-Xiong Zhang for providing the plants of tobacco.

Brestic, M., Zivcak, M., Kunderlikova, K., and Allakhverdiev, S. I. (2016). High temperature specifically affects the photoprotective responses of chlorophyll b-deficient wheat mutant lines. Photosynth. Res. 130, 251-266. doi: 10.1007/ s11120-016-0249-7

Brestic, M., Zivcak, M., Kunderlikova, K., Sytar, O., Shao, H., Kalaji, H. M., et al. (2015). Low PSI content limits the photoprotection of PSI and PSII in early growth stages of chlorophyll b-deficient wheat mutant lines. Photosynth. Res. 125, 151-166. doi: 10.1007/s11120-015-0093-1

Cruz, J. A., Avenson, T. J., Kanazawa, A., Takizawa, K., Edwards, G. E., and Kramer, D. M. (2005). Plasticity in light reactions of photosynthesis for energy production and photoprotection. J. Exp. Bot. 56, 395-406. doi: 10.1093/jxb//breakeri022 
Genty, B., Briantais, J. M., and Baker, N. R. (1989). The relationship between the quantum yield of photosynthetic electron transport and quenching of chlorophyll fluorescence. Biochim. Biophys. Acta 99, 87-92. doi: 10.1016/S03044165(89)80016-9

Havaux, M., and Davaud, A. (1994). Photoinhibition of photosynthesis in chilled potato leaves is not correlated with a loss of photosystem II activity preferential inactivation of photosystem I. Photosynth. Res. 40, 75-92. doi: 10.1007/BF00019047

Hirotsu, N., Makino, A., Ushio, A., and Mae, T. (2004). Changes in the thermal dissipation and the electron flow in the water-water cycle in rice grown under conditions of physiologically low temperature. Plant Cell Physiol. 45, 635-644. doi: $10.1093 /$ pcp/pch075

Huang, W., Cai, Y. F., Wang, J. H., and Zhang, S. B. (2018a). Chloroplastic ATP synthase plays an important role in the regulation of proton motive force in fluctuating light. J. Plant Physiol. 226, 40-47. doi: 10.1016/j.jplph.2018. 03.020

Huang, W., Quan, X., Zhang, S. B., and Liu, T. (2018b). In vivo regulation of proton motive force during photosynthetic induction. Environ. Exp. Bot. 148, 109-116. doi: 10.1007/s11120-016-0227-0

Huang, W., Tikkanen, M., and Zhang, S. B. (2018c). Photoinhibition of photosystem I in Nephrolepis falciformis depends on reactive oxygen species generated in the chloroplast stroma. Photosynth. Res. 137, 129-140. doi: 10. 1007/s11120-018-0484-1

Huang, W., Yang, S. J., Zhang, S. B., Zhang, J. L., and Cao, K. F. (2012). Cyclic electron flow plays an important role in photoprotection for the resurrection plant Paraboea rufescens under drought stress. Planta 235, 819-828. doi: 10. 1007/s00425-011-1544-3

Huang, W., Yang, Y. J., Hu, H., and Zhang, S. B. (2015). Different roles of cyclic electron flow around photosystem I under sub-saturating and saturating light intensities in tobacco leaves. Front. Plant Sci. 6:923. doi: 10.3389/fpls.2015. 00923

Huang, W., Yang, Y. J., Hu, H., and Zhang, S. B. (2016a). Moderate photoinhibition of photosystem II Pprotects photosystem I from photodamage at chilling stress in tobacco leaves. Front. Plant Sci. 7:182. doi: 10.3389/fpls.2016.00182

Huang, W., Yang, Y. J., Hu, H., and Zhang, S. B. (2016b). Seasonal variations in photosystem I compared with photosystem II of three alpine evergreen broadleaf tree species. J. Photochem. Photobiol. B Biol. 165, 71-79. doi: 10.1016/j. jphotobiol.2016.10.014

Huang, W., Yang, Y. J., Zhang, J. L., Hu, H., and Zhang, S. B. (2016c). PSI photoinhibition is more related to electron transfer from PSII to PSI rather than PSI redox state in Psychotria rubra. Photosynth. Res. 129, 85-92. doi: 10.1007/s11120-016-0275-5

Huang, W., Zhang, S. B., and Cao, K. F. (2010a). Stimulation of cyclic electron flow during recovery after chilling-induced photoinhibition of PSII. Plant Cell Physiol. 51, 1922-1928. doi: 10.1093/pcp/pcq144

Huang, W., Zhang, S. B., and Cao, K. F. (2010b). The different effects of chilling stress under moderate illumination on photosystem II compared with photosystem I and subsequent recovery in tropical tree species. Photosynth. Res. 103, 175-182. doi: 10.1007/s11120-010-9539-7

Huang, W., Zhang, S. B., and Cao, K. F. (2011). Cyclic electron flow plays an important role in photoprotection of tropical trees illuminated at temporal chilling temperature. Plant Cell Physiol. 52, 297-305. doi: 10.1093/pcp/ pcq166

Huang, W., Yang, Y. J., Zhang, J. L., Hu, H., and Zhang, S. B. (2017a). Superoxide generated in the chloroplast stroma causes photoinhibition of photosystem I in the shade-establishing tree species Psychotria henryi. Photosynth. Res. 132, 293-303. doi: 10.1007/s11120-017-0389-4

Huang, W., Yang, Y. J., and Zhang, S. B. (2017b). Specific roles of cyclic electron flow around photosystem I in photosynthetic regulation in immature and mature leaves. J. Plant Physiol. 209, 76-83. doi: 10.1016/j.jplph.2016. 11.013

Huang, W., Zhang, S. B., Xu, J. C., and Liu, T. (2017c). Plasticity in roles of cyclic electron flow around photosystem I at contrasting temperatures in the chilling-sensitive plant Calotropis gigantea. Environ. Exp. Bot. 141, 145-153. doi: 10.1016/j.envexpbot.2017.07.011

Johnson, G. N. (2011). Physiology of PSI cyclic electron transport in higher plants. Biochim. Biophys. Acta 1807, 384-389. doi: 10.1016/j.bbabio.2010.11.009
Kanazawa, A., and Kramer, D. M. (2002). In vivo modulation of nonphotochemical exciton quenching (NPQ) by regulation of the chloroplast ATP synthase. Proc. Natl. Acad. Sci. U.S.A. 99, 12789-12794. doi: 10.1073/pnas.182427499

Kanazawa, A., Ostendorf, E., Kohzuma, K., Hoh, D., Strand, D. D., SatoCruz, M., et al. (2017). Chloroplast ATP synthase modulation of the thylakoid proton motive force: implications for photosystem I and photosystem II photoprotection. Front. Plant Sci. 8:719. doi: 10.3389/fpls.2017.00719

Klughammer, C., and Schreiber, U. (2008). Saturation pulse method for assessment of energy conversion in PSI. PAM Appl. Notes 1, 11-14.

Kono, M., Noguchi, K., and Terashima, I. (2014). Roles of the cyclic electron flow around PSI (CEF-PSI) and O2-dependent alternative pathways in regulation of the photosynthetic electron flow in short-term fluctuating light in Arabidopsis thaliana. Plant Cell Physiol. 55, 990-1004. doi: 10.1093/pcp/ pcu033

Melis, A. (1999). Photosystem-II damage and repair cycle in chloroplasts: what modulates the rate of photodamage in vivo? Trends Plant Sci. 4, 130-135.

Munekage, Y., Hashimoto, M., Miyake, C., Tomizawa, K. I., Endo, T., Tasaka, M., et al. (2004). Cyclic electron flow around photosystem I is essential for photosynthesis. Nature 429, 579-582. doi: 10.1038/nature02598

Munekage, Y., Hojo, M., Meurer, J., Endo, T., Tasaka, M., and Shikanai, T. (2002). PGR5 is involved in cyclic electron flow around photosystem I and is essential for photoprotection in Arabidopsis. Cell 110, 361-371. doi: 10.1016/S00928674(02)00867-X

Munekage, Y. N., Genty, B., and Peltier, G. (2008). Effect of PGR5 impairment on photosynthesis and growth in Arabidopsis thaliana. Plant Cell Physiol. 49, 1688-1698. doi: 10.1093/pcp/pcn140

Niyogi, K. K., Grossman, A. R., and Bjorkman, O. (1998). Arabidopsis mutants define a central role for the xanthophyll cycle in the regulation of photosynthetic energy conversion. Plant Cell 10, 1121-1134. doi: 10.1105/tpc.10.7.1121

Rott, M., Martins, N. F., Thiele, W., Lein, W., Bock, R., Kramer, D. M., et al. (2011). ATP synthase repression in tobacco restricts photosynthetic electron transport, $\mathrm{CO} 2$ assimilation, and plant growth by overacidification of the thylakoid lumen. Plant Cell 23, 304-321. doi: 10.1105/tpc.110.079111

Sacksteder, C. A., Jacoby, M. E., and Kramer, D. M. (2001). A portable, nonfocusing optics spectrometer (NoFOSpec) for measurements of steady-state absorbance changes in intact plants. Photosynth. Res. 70, 231-240. doi: 10.1023/ A: 1017906626288

Sacksteder, C. A., and Kramer, D. M. (2000). Dark interval relaxation kinetics of absorbance changes as a quantitative probe of steady-state electron transfer. Photosynth. Res. 66, 145-158. doi: 10.1023/A:1010785912271

Sejima, T., Takagi, D., Fukayama, H., Makino, A., and Miyake, C. (2014). Repetitive short-pulse light mainly inactivates photosystem I in sunflower leaves. Plant Cell Physiol. 55, 1184-1193. doi: 10.1093/pcp/pcu061

Shikanai, T., and Yamamoto, H. (2017). Contribution of cyclic and pseudo-cyclic electron transport to the formation of proton motive force in chloroplasts. Mol. Plant 10, 20-29. doi: 10.1016/j.molp.2016. 08.004

Sonoike, K., Kamo, M., Hihara, Y., Hiyama, T., and Enami, I. (1997). The mechanism of the degradation of $\mathrm{psaB}$ gene product, one of the photosynthetic reaction center subunits of photosystem I upon photoinhibition. Photosynth. Res. 53, 55-63. doi: 10.1023/A:1005852330671

Sonoike, K., and Terashima, I. (1994). Mechanism of photosystem-I photoinhibition in leaves of Cucumis sativus L. Planta 194, 287-293. doi: $10.1007 / \mathrm{BF} 01101690$

Sukhov, V. (2016). Electrical signals as mechanism of photosynthesis regulation in plants. Photosynth. Res. 130, 373-387. doi: 10.1007/s11120-016-0270-x

Sukhov, V., Surova, L., Morozova, E., Sherstneva, O., and Vodeneev, V. (2016). Changes in $\mathrm{H}+$-ATP synthase activity, proton electrochemical gradient, and $\mathrm{pH}$ in pea chloroplast can be connected with variation potential. Front. Plant Sci. 7:1092. doi: 10.3389/fpls.2016.01092

Suorsa, M., Jarvi, S., Grieco, M., Nurmi, M., Pietrzykowska, M., Rantala, M., et al. (2012). PROTON GRADIENT REGULATION5 is essential for proper acclimation of Arabidopsis photosystem I to naturally and artificially fluctuating light conditions. Plant Cell 24, 2934-2948. doi: 10.1105/tpc.112. 097162

Suorsa, M., Rossi, F., Tadini, L., Labs, M., Colombo, M., Jahns, P., et al. (2016). PGR5-PGRL1-dependent cyclic electron transport modulates linear electron 
transport rate in Arabidopsis thaliana. Mol. Plant 9, 271-288. doi: 10.1016/j. molp.2015.12.001

Surova, L., Sherstneva, O., Vodeneev, V., and Sukhov, V. (2016). Variation potential propagation decreases heat-related damage of pea photosystem I by 2 different pathways. Plant Signal. Behav. 11:e1145334. doi: 10.1080/15592324. 2016.1145334

Takagi, D., Amako, K., Hashiguchi, M., Fukaki, H., Ishizaki, K., Goh, T., et al. (2017). Chloroplastic ATP synthase builds up proton motive force for preventing reactive oxygen species production in photosystem I. Plant J. 91, 306-324. doi: 10.1111/tpj.13566

Takagi, D., Takumi, S., Hashiguchi, M., Sejima, T., and Miyake, C. (2016). Superoxide and singlet oxygen produced within the thylakoid membranes both cause photosystem I photoinhibition. Plant Physiol. 171, 1626-1634. doi: 10. $1104 /$ pp. 16.00246

Takizawa, K., Kanazawa, A., and Kramer, D. M. (2008). Depletion of stromal Pi induces high 'energy-dependent' antenna exciton quenching ( $\mathrm{qE}$ ) by decreasing proton conductivity at CFO-CF1 ATP synthase. Plant Cell Environ. 31, 235243. doi: 10.1111/j.1365-3040.2007.01753.x

Terashima, I., Funayama, S., and Sonoike, K. (1994). The site of photoinhibition in leaves of Cucumis sativus L. at low temperatures is photosystem. I., not photosystem II. Planta 193, 300-306.

Tikkanen, M., and Aro, E. M. (2014). Integrative regulatory network of plant thylakoid energy transduction. Trends Plant Sci. 19, 10-17. doi: 10.1016/j. tplants.2013.09.003

Tikkanen, M., Mekala, N. R., and Aro, E. M. (2014). Photosystem II photoinhibition-repair cycle protects Photosystem I from irreversible damage. Biochim. Biophys. Acta 1837, 210-215. doi: 10.1016/j.bbabio.2013.10.001

Tikkanen, M., Rantala, S., and Aro, E. M. (2015). Electron flow from PSII to PSI under high light is controlled by PGR5 but not by PSBS. Front. Plant Sci. 6:521. doi: $10.3389 /$ fpls.2015.00521

Wang, C., Yamamoto, H., and Shikanai, T. (2015). Role of cyclic electron transport around photosystem I in regulating proton motive force. Biochim. Biophys. Acta 1847, 931-938. doi: 10.1016/j.bbabio.2014.11.013

Yamamoto, H., Takahashi, S., Badger, M. R., and Shikanai, T. (2016). Artificial remodelling of alternative electron flow by flavodiiron proteins in Arabidopsis. Nat. Plants 2:16012. doi: 10.1038/nplants.2016.12

Yamori, W., Makino, A., and Shikanai, T. (2016). A physiological role of cyclic electron transport around photosystem I in sustaining photosynthesis under fluctuating light in rice. Sci. Rep. 6:20147. doi: 10.1038/srep20147
Yamori, W., Sakata, N., Suzuki, Y., Shikanai, T., and Maniko, A. (2011). Cyclic electron flow around photosystem I via chloroplast $\mathrm{NAD}(\mathrm{P}) \mathrm{H}$ dehydrogenase $(\mathrm{NDH})$ complex performs a significant physiological role during photosynthesis and plant growth at low temperature in rice. Plant J. 68, 966-976. doi: 10.1111/j.1365-313X.2011.04747.x

Yamori, W., Shikanai, T., and Makino, A. (2015). Photosystem I cyclic electron flow via chloroplast NADH dehydrogenase-like complex performs a physiological role for photosynthesis at low light. Sci. Rep. 5:13908. doi: 10.1038/srep13908

Zhang, S. P., and Scheller, H. V. (2004). Photoinhibition of photosystem I at chilling temperature and subsequent recovery in Arabidopsis. Plant Cell Physiol. 45, 1595-1602. doi: 10.1093/pcp/pch180

Zhou, Y. H., Yu, J. Q., Huang, L. F., and Nogues, S. (2004). The relationship between $\mathrm{CO} 2$ assimilation, photosynthetic electron transport and waterwater cycle in chill-exposed cucumber leaves under low light and subsequent recovery. Plant Cell Environ. 27, 1503-1514. doi: 10.1111/j.1365-3040.2004. 01255.x

Zivcak, M., Brestic, M., Balatova, Z., Drevenakova, P., Olsovska, K., Kalaji, H. M., et al. (2013). Photosynthetic electron transport and specific photoprotective responses in wheat leaves under drought stress. Photosynth. Res. 117, 529-546. doi: 10.1007/s11120-013-9885-3

Zivcak, M., Brestic, M., Kunderlikova, K., Sytar, O., and Allakhverdiev, S. I. (2015). Repetitive light pulse-induced photoinhibition of photosystem I severely affects CO2 assimilation and photoprotection in wheat leaves. Photosynth. Res. 126, 449-463. doi: 10.1007/s11120-015-0121-1

Zivcak, M., Kalaji, H. M., Shao, H. B., Olsovska, K., and Brestic, M. (2014). Photosynthetic proton and electron transport in wheat leaves under prolonged moderate drought stress. J. Photochem. Photobiol. B Biol. 137, 107-115. doi: 10.1016/j.jphotobiol.2014.01.007

Conflict of Interest Statement: The authors declare that the research was conducted in the absence of any commercial or financial relationships that could be construed as a potential conflict of interest.

Copyright (c) 2018 Yang, Zhang and Huang. This is an open-access article distributed under the terms of the Creative Commons Attribution License (CC BY). The use, distribution or reproduction in other forums is permitted, provided the original author(s) and the copyright owner(s) are credited and that the original publication in this journal is cited, in accordance with accepted academic practice. No use, distribution or reproduction is permitted which does not comply with these terms. 